\title{
Reactive processing of maleic anhydride-grafted poly(butylene succinate) and the compatibilizing effect on poly(butylene succinate) nanocomposites
}

\author{
Y. J. Phua ${ }^{1,2}$, W. S. Chow ${ }^{1,2}$, Z. A. Mohd Ishak ${ }^{1,2 *}$ \\ ${ }^{1}$ Cluster for Polymer Composites, Engineering and Technology Research Platform, Engineering Campus, Universiti Sains \\ Malaysia, 14300 Nibong Tebal, Penang, Malaysia. \\ ${ }^{2}$ School of Materials and Mineral Resources Engineering, Engineering Campus, Universiti Sains Malaysia, 14300 Nibong \\ Tebal, Penang, Malaysia
}

Received 27 September 2012; accepted in revised form 8 December 2012

\begin{abstract}
In this study, maleic anhydride-grafted poly(butylene succinate) (PBS-g-MA) was synthesized via reactive meltgrafting process using different initiator contents. The grafting efficiency was increased with the initiator content, manifested by the higher degree of grafting in PBS-g-MA. The grafting reaction was confirmed through Fourier transform infrared (FTIR) spectroscopy and nuclear magnetic resonance (NMR) spectroscopy. Then, PBS-g-MA was incorporated into organo-montmorillonite (OMMT) filled poly(butylene succinate) (PBS) nanocomposites as compatibilizer. Mechanical properties of PBS nanocomposites were enhanced after compatibilized with PBS-g-MA, due to the better dispersion of OMMT in PBS matrix and the improved filler-matrix interfacial interactions. This was verifiable through X-ray diffraction (XRD), transmission electron microscopy (TEM) and scanning electron microscopy (SEM). Differential scanning calorimetry (DSC) showed that the degree of crystallinity and melting temperature increased after addition of PBS-g-MA. However, the presence of PBS-g-MA did not favor the thermal stability of the nanocomposites, as reported in the thermogravimetry (TGA).
\end{abstract}

Keywords: nanocomposites, biodegradable polymers, reinforcements, mechanical properties

\section{Introduction}

The production of polymer/organoclay nanocomposites to enhance the performance of materials has been a rapidly expanding field of research. Organomontmorillonite (OMMT) is one of the commercial organoclays that has been widely utilized as reinforcing filler in polymer nanocomposites [1-3]. Numerous authors have reported on the enhancement in strength and modulus [4-6], gas barrier [7] and flame retardant properties [8-9] of polymer/OMMT nanocomposites. In recent years, attention has been devoted to the nanocomposites based on biodegrad- able polymers and organoclay due to the increasing awareness on the plastic waste pollution.

Poly(butylene succinate) (PBS) is a biodegradable polyester with many desirable properties including biodegradability, melt processability, thermal and chemical resistance [10-14]. Fujimaki [13] has compared the properties between the biodegradable PBS and the conventional plastic packaging materials. He reported that the yield strength of PBS (Bionolle \#1020) was 264\% higher than that of low-density polyethylene (LDPE), and was $10.3 \%$ higher than that of polypropylene (PP). In this research, OMMT was incorporated into the PBS matrix in order to

\footnotetext{
${ }^{*}$ Corresponding author, e-mail: zarifin.ishak@googlemail.com (C) BME-PT
} 
produce a 'green' nanocomposite, which is focusing on the potential application in the environmentalfriendly packaging films. In our previous work, the effects of OMMT loading on the mechanical and rheological properties of biodegradable PBS/OMMT nanocomposites were reported. The optimum mechanical properties of PBS nanocomposites were observed at $2 \mathrm{wt} \%$ OMMT loading [15-16]. However, the improvement is rather limited due to the low polarity of PBS, which restricted the dispersion of clay platelets because of the absence of any strong interactions [17]. Therefore, to obtain a homogeneous dispersion of OMMT in PBS matrix has become a major challenge. Compatibilization turns out to be the most potential way to further enhance the properties of PBS/OMMT nanocomposites.

Maleic anhydride (MA)-grafted polymers have been used as compatibilizers in many composite systems, by reason of their polar functional group that will improve the filler-matrix interactions [18-21]. LópezQuintanilla et al. [22] reported on the better interfacial adhesion between PP and clay after compatibilized with MA-grafted PP, subsequently improved the mechanical properties of the nanocomposites. Kusmono et al. [23] discovered that the incorporation of MA grafted styrene-ethylene/butylenestyrene was able to enhance the strength and ductility of polyamide 6/polypropylene nanocomposites. Although studies on PBS nanocomposites are rather abundant [10-12], study on the PBS nanocomposites compatibilized with MA-grafted polymers is rare. To date, PBS-g-MA is not commercially available and there is limited literature reported on this material. In this study, PBS-g-MA was produced through reactive melt-grafting method in the presence of dicumyl peroxide (DCP) as initiator at various contents, i.e. 1 and $1.5 \mathrm{phr}$. At our previous research, the optimum mechanical properties of PBS nanocomposites were observed at $2 \mathrm{wt} \%$ OMMT loading [15-16]. Hence, as an extension of the previous study, PBS-g-MA was added into the $2 \mathrm{wt} \%$ OMMT filled PBS nanocomposites, to investigate the effects of initiator content on the grafting efficiency, and its compatibilizing effects on PBS nanocomposites. In addition, the mechanical, thermal and morphological properties of PBS/OMMT nanocomposites were studied.

\section{Experimental}

\subsection{Materials}

PBS (Bionolle \#1020) was supplied by Showa Highpolymer Co., Ltd., Japan with MFI value of $25 \mathrm{~g} / 10 \mathrm{~min}\left(190^{\circ} \mathrm{C}, 2.16 \mathrm{~kg}\right)$ and melting temperature of $115^{\circ} \mathrm{C}$. OMMT (Nanomer ${ }^{\circledR}$ I.30TC, Nanocor Inc, USA) with cation exchange capacity (CEC) of 110 mequiv/100 g, containing MMT (70 wt\%) intercalated by octadecylamine (30 wt $\%$ ) was used. DCP (Aldrich Luperox ${ }^{\circledR}$, purity $\geq 99.0 \%$ ) from Sigma-Aldrich Inc, USA was used as initiator. MA (purity $\geq 99.8 \%$ ) was obtained from R\&M Chemicals, UK.

\subsection{Synthesis of PBS-g-MA}

First, PBS, MA and DCP were physically premixed. The reactive grafting process was carried out in an internal mixer (Haake Polydrive R600, Germany) at $135^{\circ} \mathrm{C}$ for $7 \mathrm{~min}$. Two different PBS-g-MA, varying from the initiator content, labeled as $\mathrm{C} 1$ and $\mathrm{C} 2$ were produced as shown in Table 1. After that, purification process was carried out. PBS-g-MA was refluxed in chloroform for $4 \mathrm{~h}$, and the hot solution was filtered into cold methanol. The precipitated polymer was washed with methanol several times, in order to remove any unreacted reagents, followed by drying in an oven at $60^{\circ} \mathrm{C}$ for $24 \mathrm{~h}$. The purified PBS-g-MA was obtained.

Table 1. Compositions for a Preparation of PBS-g-MA

\begin{tabular}{|l|c|c|}
\hline \multirow{2}{*}{ Component } & C1 & C2 \\
\cline { 2 - 3 } & Amount [phr] & Amount [phr] \\
\hline PBS & 100 & 100 \\
\hline MA & 10 & 10 \\
\hline DCP & 1 & 1.5 \\
\hline
\end{tabular}

${ }^{*} \mathrm{phr}=$ part per hundred resin

\subsection{Degree of grafting determination}

The degree of grafting $\left(G_{\mathrm{d}}\right)$ for PBS-g-MA was determined through titration. $1 \mathrm{~g}$ of purified PBS-gMA was refluxed in $100 \mathrm{~mL}$ of chloroform for $1 \mathrm{~h}$. Then, $10 \mathrm{~mL}$ of distilled water were added. It was titrated immediately with $0.025 \mathrm{M}$ potassium hydroxide $(\mathrm{KOH})$ using phenolphthalein as indicator. $G_{\mathrm{d}}$ can be calculated as shown by Equation (1):

$G_{\mathrm{d}}[\%]=\frac{N\left(V_{1}-V_{0}\right) \cdot 98.06}{2 \cdot W \cdot 1000} \cdot 100 \%$ 
where $N$ is the $\mathrm{KOH}$ concentration $[\mathrm{M}], W$ is the sample weight [g], $V_{0}$ and $V_{1}$ is the $\mathrm{KOH}$ volume $[\mathrm{mL}]$ for blank solution and for titration of PBS-gMA, respectively.

\subsection{Fourier transform infrared (FTIR) spectroscopy}

FTIR analysis was carried out on the PBS-g-MA at ambient temperature by using Perkin-Elmer Spectrum One FT-IR Spectrometer (USA). It was performed through the scanning wavelength from $4000-550 \mathrm{~cm}^{-1}$ with 32 scanning times.

\subsection{Nuclear magnetic resonance (NMR) spectroscopy}

NMR test were conducted in deuterated chloroform $\left(\mathrm{CDCl}_{3}\right)$ solution under ambient temperature on a Bruker Avance $300 \mathrm{MHz}$ spectrometer (Germany) with $13.2 \mu$ s pulse and acquisition time of $3.0 \mathrm{~s}$. Tetramethylsilane (TMS) was applied as internal chemical shift standard. Two-dimensional correlation spectroscopy (COSY) was recorded with relaxation-delay time of $1.62 \mathrm{~s}$ and sweep width of $1930.5 \mathrm{~Hz}$.

\subsection{Gel permeation chromatography (GPC)}

The molecular weight of PBS was measured by gel permeation chromatography (GPC) analysis. GPC analysis was performed at $40^{\circ} \mathrm{C}$ on an Agilent Technologies 1200 Series GPC system (USA) equipped with a refractive index detector (RID) and SHODEX K-806M and SHODEX K-802 columns. The calibration of the columns was carried out using a polystyrene standard of known molecular weight and polydispersity. The samples were then dissolved in chloroform at ambient temperature, followed by filtration to eliminate the contaminants. Chloroform was used as the eluent with a flow rate of $0.8 \mathrm{~mL} / \mathrm{min}$, and the injected sample volume was $50 \mu \mathrm{L}$ with a polymer concentration of $1 \mathrm{mg} / \mathrm{mL}$. The weight-average molecular weight $\left(M_{\mathrm{w}}\right)$ and number-average molecular weight $\left(M_{\mathrm{n}}\right)$ were obtained from the GPC analysis.

\subsection{Preparation of nanocomposites}

PBS nanocomposites were prepared by the addition of $2 \mathrm{wt} \%$ OMMT and $5 \mathrm{wt} \%$ PBS-g-MA into the PBS resin. PBS, OMMT and PBS-g-MA were physically premixed and melt-mixed in an internal mixer (Haake PolyDrive R600, Germany) at $135^{\circ} \mathrm{C}$ for
5 min with a rotary speed of $50 \mathrm{rpm}$. It was then molded on a compression molding machine (GT 7014-A30C, Taiwan) at $135^{\circ} \mathrm{C}$ and 3 min into various shapes of specimen.

\subsection{Mechanical properties}

Mechanical tests were performed using universal testing machine (Instron 3366, Instron Co., Ltd., USA) at $23 \pm 2{ }^{\circ} \mathrm{C}$ and $50 \pm 5 \%$ relative humidity. Tensile test was carried out using ASTM D638-03 (Type IV) with a gauge length of $50 \mathrm{~mm}$ and a cross-head speed of $5 \mathrm{~mm} / \mathrm{min}$. Flexural test (threepoint bending) was performed according to ASTM D790-03 with a support span length of $50 \mathrm{~mm}$ and a cross-head speed of $5 \mathrm{~mm} / \mathrm{min}$.

\subsection{X-ray diffraction (XRD)}

XRD analysis was carried out with PANalytical X'pert Pro Mrd PW2040 XRD diffractometer (Netherlands) in a scan range from $2-10^{\circ}$ and $2.0^{\circ} / \mathrm{min}$ scanning rate. The $\mathrm{X}$-ray source was $\mathrm{Cu}-$ $\mathrm{K}_{\alpha}$ radiation with a wavelength $(\lambda)$ of $0.154 \mathrm{~nm}$. The interlayer spacing of OMMT was calculated from $d_{001}$-reflections using Bragg's equation: $n \lambda=$ $2 d_{001} \cdot \sin \theta$, where $\theta$ is the measured diffraction angle [24].

\subsection{Transmission electron microscopy (TEM)}

The morphologies of the nanocomposite samples were observed using an Energy Filter Transmission Microscope (EFTEM) (Zeiss Libra 120, Netherlands) operated at $200 \mathrm{kV}$. The ultrathin sections of sample with the thickness $70-80 \mathrm{~nm}$ were prepared via ultramicrotomy technique using Reichert Ultramicrotome Supernova.

\subsection{Scanning electron microscopy (SEM)}

The tensile-fractured surface of the samples was observed under a field-emission scanning electron microscope (FESEM) (Zeiss LEO Supra 35VP, Germany). Prior to the observations, the samples were sputter-coated with a thin layer of gold to avoid electrical charging during examination.

\subsection{Differential scanning calorimetry (DSC)}

The DSC analysis was carried out using PerkinElmer DSC-6 (USA) machine in a nitrogen atmosphere. Sample was heated from 30 to $150^{\circ} \mathrm{C}$ at a heating rate of $10^{\circ} \mathrm{C} / \mathrm{min}$. The sample was then cooled 
from 150 to $30^{\circ} \mathrm{C}$ at a same heating rate. Next, second heating was performed from 30 to $150^{\circ} \mathrm{C}$. Finally, it is cooled to $30^{\circ} \mathrm{C}$. The thermal behavior of PBS nanocomposites is studied from the second heating and cooling in DSC in order to eliminate the thermal history. Degree of crystallinity $\left(\chi_{c}\right)$ was calculated by using Equations (2) and (3):

For pure PBS,

$\chi_{\mathrm{c}}=\frac{\Delta H_{\mathrm{c}}}{\Delta H_{\mathrm{m}}^{0}} \cdot 100 \%$

where $\Delta H_{\mathrm{c}}$ crystallization enthalpy of sample, $\Delta H_{\mathrm{m}}^{0}$ melting enthalpy of $100 \%$ crystalline PBS $(110.3 \mathrm{~J} / \mathrm{g})[25]$.

For polymer nanocomposites,

$\chi_{\mathrm{c}}=\frac{\Delta H_{\mathrm{c}}}{\Delta H_{\mathrm{m}}^{0}\left(1-W_{\mathrm{f}}\right)} \cdot 100 \%$

where $W_{\mathrm{f}}$ weight fraction of fillers in the nanocomposite.

\subsection{Thermogravimetry (TGA)}

TGA was conducted in the Perkin-Elmer Pyris 6 TGA Analyzer (USA) from room temperature to $700^{\circ} \mathrm{C}$ at the heating rate of $10^{\circ} \mathrm{C} / \mathrm{min}$ under nitrogen atmosphere.

\section{Results and discussion}

\subsection{Characterizations of PBS-g-MA}

\subsubsection{Degree of grafting $\left(G_{\mathrm{d}}\right)$ determination}

In the previous study, Mani et al. [26] performed the grafting of MA onto PBS by varying the initiator content from $0.3-1.0 \mathrm{wt} \%$. They reported that the grafting efficiency was the highest at $1.0 \mathrm{wt} \%$ of initiator. By using this as a reference, in this study, 1.0 and $1.5 \mathrm{phr}$ of initiator was incorporated. Generally, $G_{\mathrm{d}}$ is influenced by various factors such as monomer and initiator concentration, temperature, rotor speed and residence time [26, 27]. In the present research, other parameters were kept constant. Therefore, the changes in $G_{\mathrm{d}}$ are mainly attributed by the initiator concentration. Table 2 shows that C1 possess $G_{\mathrm{d}}$ of $3.89 \%$, while C2 exhibits a $G_{\mathrm{d}}$ of

Table 2. Degree of grafting and molecular weight at different initiator concentrations

\begin{tabular}{|c|c|c|c|c|}
\hline Compatibilizer & $\begin{array}{c}\text { DCP } \\
\text { concentration } \\
\text { [phr] }\end{array}$ & $\begin{array}{c}\text { Degree of } \\
\text { grafting } \\
{[\mathbf{\%}]}\end{array}$ & $\begin{array}{c}\mathbf{M}_{\mathbf{w}} \\
{[\mathbf{g} / \mathbf{m o l}]}\end{array}$ & $\begin{array}{c}\mathbf{M}_{\mathbf{n}} \\
{[\mathbf{g} / \mathbf{m o l}]}\end{array}$ \\
\hline $\mathrm{C} 1$ & 1.0 & 3.89 & 28620 & 14450 \\
\hline $\mathrm{C} 2$ & 1.5 & 4.84 & 24620 & 12450 \\
\hline
\end{tabular}

4.84\%. This reveals that the grafting efficiency increased as the initiator content increased, owing to the increase radical formation through the decomposition of initiator. Higher radical concentration would provide higher chain transfer to the polymer backbone and hence, higher the grafting efficiency. Note that high initiator concentration may cause crosslinking to the polymers. $\mathrm{C} 1$ and $\mathrm{C} 2$ were completely dissolved in chloroform, indicating no crosslinking takes place in the grafting process.

The $G_{\mathrm{d}}$ of PBS-g-MA that synthesized in this work is appeared to be higher than that of the conventional grafted polymers such as MA-grafted PP, with the $G_{\mathrm{d}}$ ranged between $0.5-1.2 \%$ [28]. This shows the potential of PBS-g-MA to be applied as compatibilizer in the polymer composite system, with respect to its higher ability to diffuse into the polymer matrix and provide enough sites for attachment to the fillers.

Besides that, the molecular weight of $\mathrm{C} 1$ and $\mathrm{C} 2$ was determined through gel permeation chromatography (GPC) analysis. The weight-average molecular weight $\left(M_{\mathrm{w}}\right)$ and number-average molecular weight $\left(M_{\mathrm{n}}\right)$ were determined and shown in Table 2. Based on the datasheet, the initial $M_{\mathrm{w}}$ of the PBS is $1.4 \cdot 10^{5} \mathrm{~g} / \mathrm{mol}$. Thus, this shows that as the PBS is grafted with MA, the molecular weight is lowered as a result from chain degradation via the beta-scission reaction [26].

\subsubsection{Fourier transform infrared (FTIR) spectroscopy}

The performance of the grafting process was further evaluated through FTIR spectroscopy, as reported in Figure 1. The peak at $917 \mathrm{~cm}^{-1}$ corresponds to the $-\mathrm{C}-\mathrm{OH}$ bending in the carboxylic acid groups of PBS. The bands at $1044-1046 \mathrm{~cm}^{-1}$ were due to

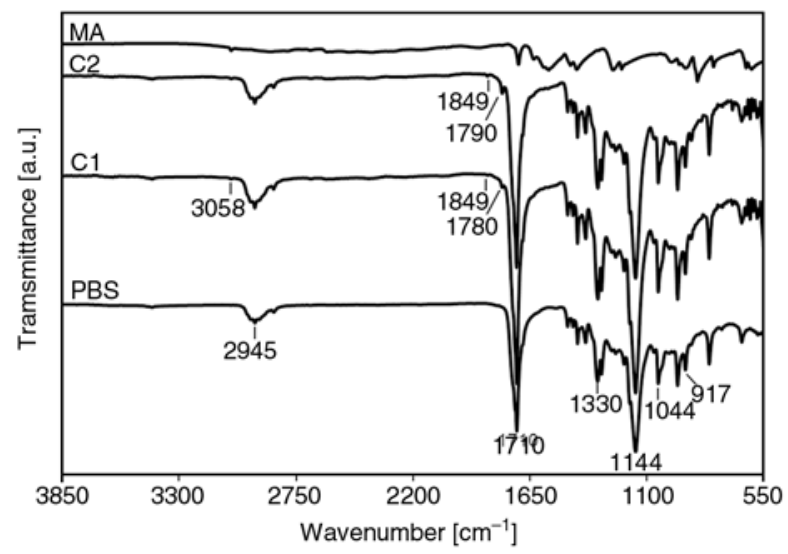

Figure 1. FTIR spectra of PBS, PBS-g-MA and MA 
-O-C $-\mathrm{C}-$ stretching vibrations in PBS. Peaks in the range of 1144-1264 $\mathrm{cm}^{-1}$ resulted from the stretching of the $-\mathrm{C}-\mathrm{O}-\mathrm{C}-$ group in the ester linkages of PBS. The band at the $1710-1713 \mathrm{~cm}^{-1}$ region was attributed to the $\mathrm{C}=\mathrm{O}$ stretching vibrations of ester groups in PBS. Meanwhile, the peaks at 1330 and $2945 \mathrm{~cm}^{-1}$ were assigned to the symmetric and asymmetric deformational vibrations of $-\mathrm{CH}_{2}-$ groups in the PBS main chains, respectively [29].

There is a clear signal at the transmittance bands of 1780 and $1849 \mathrm{~cm}^{-1}$ in the grafted PBS, while were absent in the neat PBS. These bands are assigned to the symmetric $\left(1780 \mathrm{~cm}^{-1}\right)$ and asymmetric $\left(1849 \mathrm{~cm}^{-1}\right)$ stretching of $\mathrm{C}=\mathrm{O}$ bonds for the succinic anhydride groups $[27,30]$. Higher peak intensities were also observed on $\mathrm{C} 2$ at the 1780 and $1849 \mathrm{~cm}^{-1}$ bands as compared to $\mathrm{C} 1$, corresponded to higher content of succinic anhydride groups in $\mathrm{C} 2$. Furthermore, an additional band at $3058 \mathrm{~cm}^{-1}$ was found in PBS-g-MA and neat MA, ascribed to the $=\mathrm{CH}_{2}$ vibration in the cyclic MA.

\subsubsection{Nuclear magnetic resonance (NMR) spectroscopy}

The ${ }^{1} \mathrm{H}-\mathrm{NMR}$ spectra of pure PBS and PBS-g-MA are shown in Figure 2. The ${ }^{1} \mathrm{H}-\mathrm{NMR}$ resonance signal of pure PBS appearing at $2.55 \mathrm{ppm}$ was associated with the methylene protons $\left(H_{\mathrm{a}}\right)$ in the succinic moiety. The resonances at 4.05 and $1.64 \mathrm{ppm}$ were respectively assigned to the methylene protons $\alpha$ $\left(H_{\mathrm{b}}\right)$ and $\beta\left(H_{\mathrm{c}}\right)$ in the 1,4-butanediol unit. An additional signal is observed in the PBS-g-MA spectra at approximate $3.7 \mathrm{ppm}$ region (Figure $2 \mathrm{~b}$ and $2 \mathrm{c}$ ), which is related to the resonance of the methane proton formed due to the grafting of MA [26]. This supports the evidence that MA is attached to the polymer chains after the reactive grafting process.

The 2D COSY ${ }^{1} \mathrm{H}-\mathrm{NMR}$ spectra (Figure 3) provides additional information on the grafting mechanism, which reveals the coupling relationships between the protons presence in the grafted PBS. In Figure $3 \mathrm{a}$, the off-diagonal peaks or cross correlated peaks show a single coupling interaction between the neighboring carbon atoms in the 1,4butanediol unit $\left(H_{\mathrm{bc}}\right)$ of pure PBS. A similar coupling interaction is seen in the PBS-g-MA, as shown in Figure $3 \mathrm{~b}$ and $3 \mathrm{c}$. However, there is an additional coupling interaction between the methine proton of the anhydride with protons of the $\alpha$ carbon atom $\left(H_{\mathrm{b}^{\prime}}\right)$ in the 1,4-butanediol unit. This result suggests
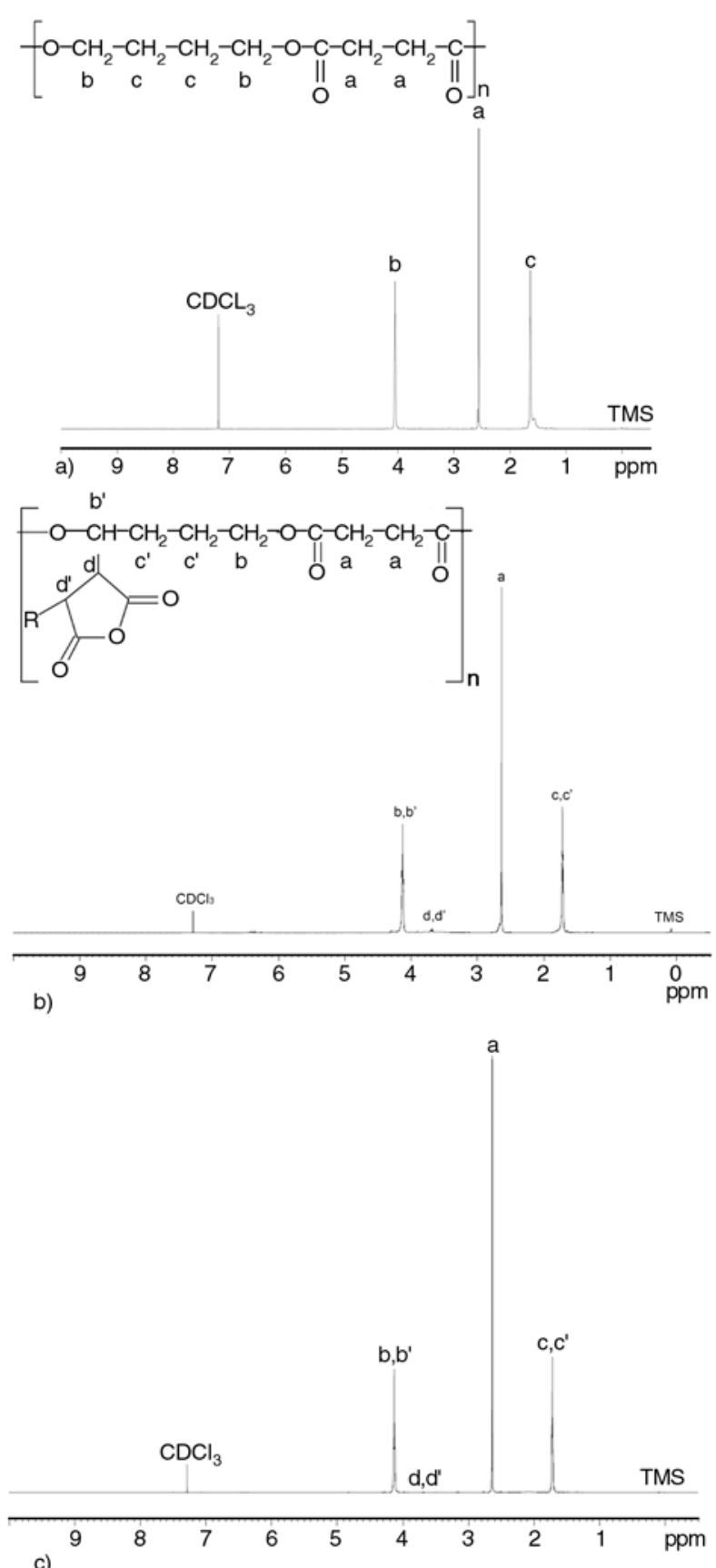

Figure 2. ${ }^{1} \mathrm{H}-\mathrm{NMR}$ spectra of (a) pure PBS, (b) $\mathrm{C} 1$ and (c) $\mathrm{C} 2$

that the grafting reaction take place at the diol unit of PBS, which is proposed in Figure 4. Thus, the COSY ${ }^{1} \mathrm{H}-\mathrm{NMR}$ demonstrated a successful construction of the PBS-g-MA product.

Figure 4. represents a proposed scheme of the reactions during the reactive melt grafting of PBS-gMA. The initiator decomposes at the initial step to form primary radicals (Scheme I). These primary radicals abstract the hydrogen atom from PBS backbone and yield PBS radicals (Scheme II). Scheme III shows the grafting of MA molecules onto the PBS radicals to form PBS-MA radicals, and followed by 
a)
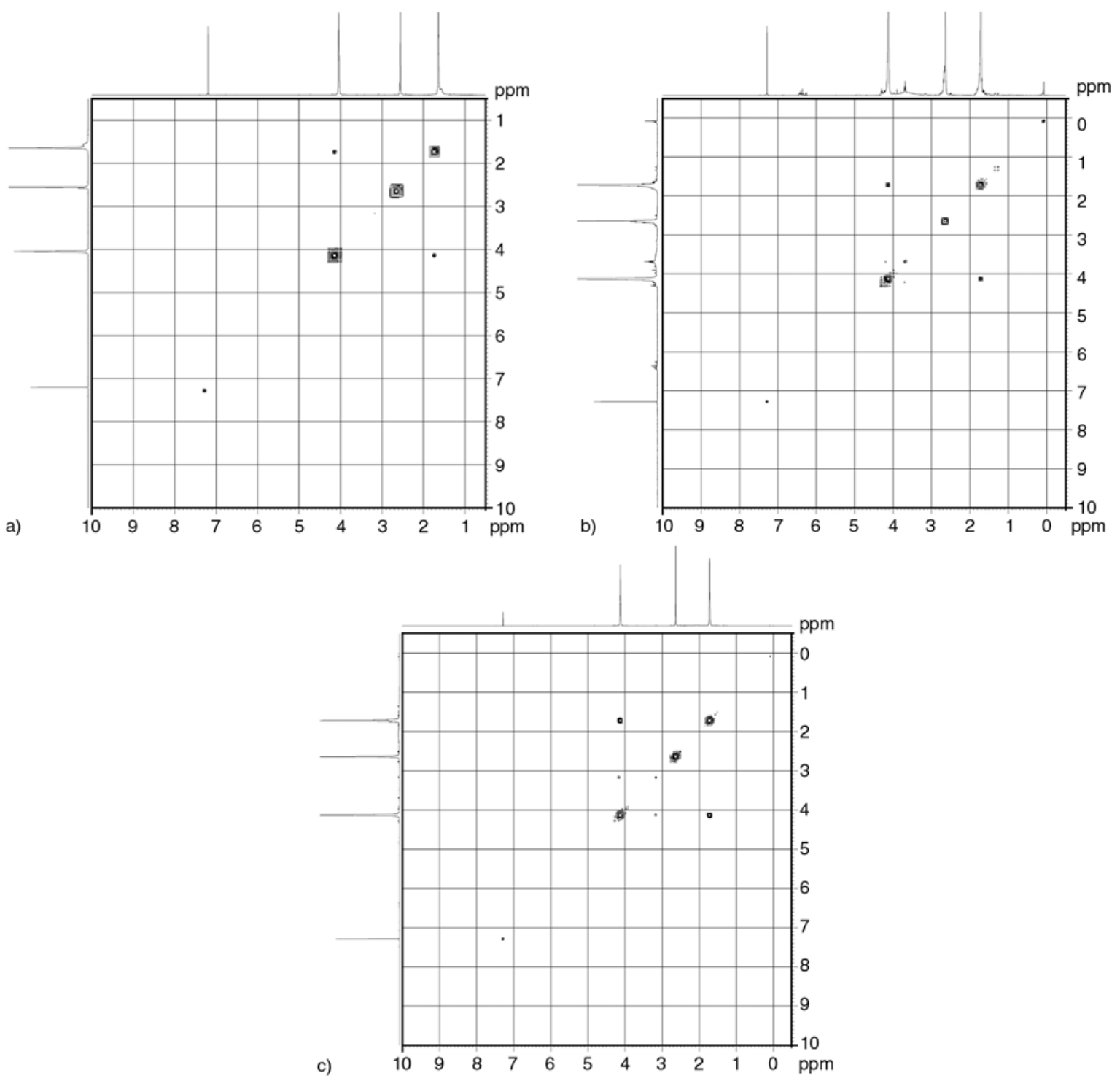

Figure 3. 2D COSY ${ }^{1} \mathrm{H}-\mathrm{NMR}$ spectra of (a) pure PBS, (b) $\mathrm{C} 1$ and (c) $\mathrm{C} 2$

various termination reactions. The PBS-MA radicals might undergo hydrogen transfer from another polymer chains, MA, or the initiator (Scheme IV) and form the final product of PBS-g-MA. Scheme V presents the possible reactions of PBS-MA radicals with other radicals in the system, such as MA, PBS or primary radicals to form a different structure of PBS-g-MA.

\subsection{Characterizations of nanocomposites}

\subsubsection{Mechanical tests}

The mechanical properties of PBS nanocomposites are presented in Table 3. It can be seen that the presence of PBS-g-MA decreased the tensile and flexural strength, as well as the elongation at break of PBS. The low molecular weight of PBS-g-MA is believed to responsible for this reduction. It was reported in our previous publication that the mechanical strength and modulus were increased, after incorporation of $2 \mathrm{wt} \%$ OMMT into PBS to form a nanocomposite [15]. After compatibilization with $\mathrm{C} 2$, tensile and flexural strength of the nanocomposites are improved by 10.4 and $6.1 \%$, respectively. The polar MA groups may interact with the amine groups on the OMMT surface by forming hydrogen bonding on one side, and with the carbonyl groups on the PBS chains on the other side. This may consequently improve the filler-matrix interaction, meanwhile, enhance the filler dispersion through the intercalation of MA groups between the silicate galleries [19, 21, 31]. Besides that, the higher amount of grafted MA contained in $\mathrm{C} 2$ is able to provide 

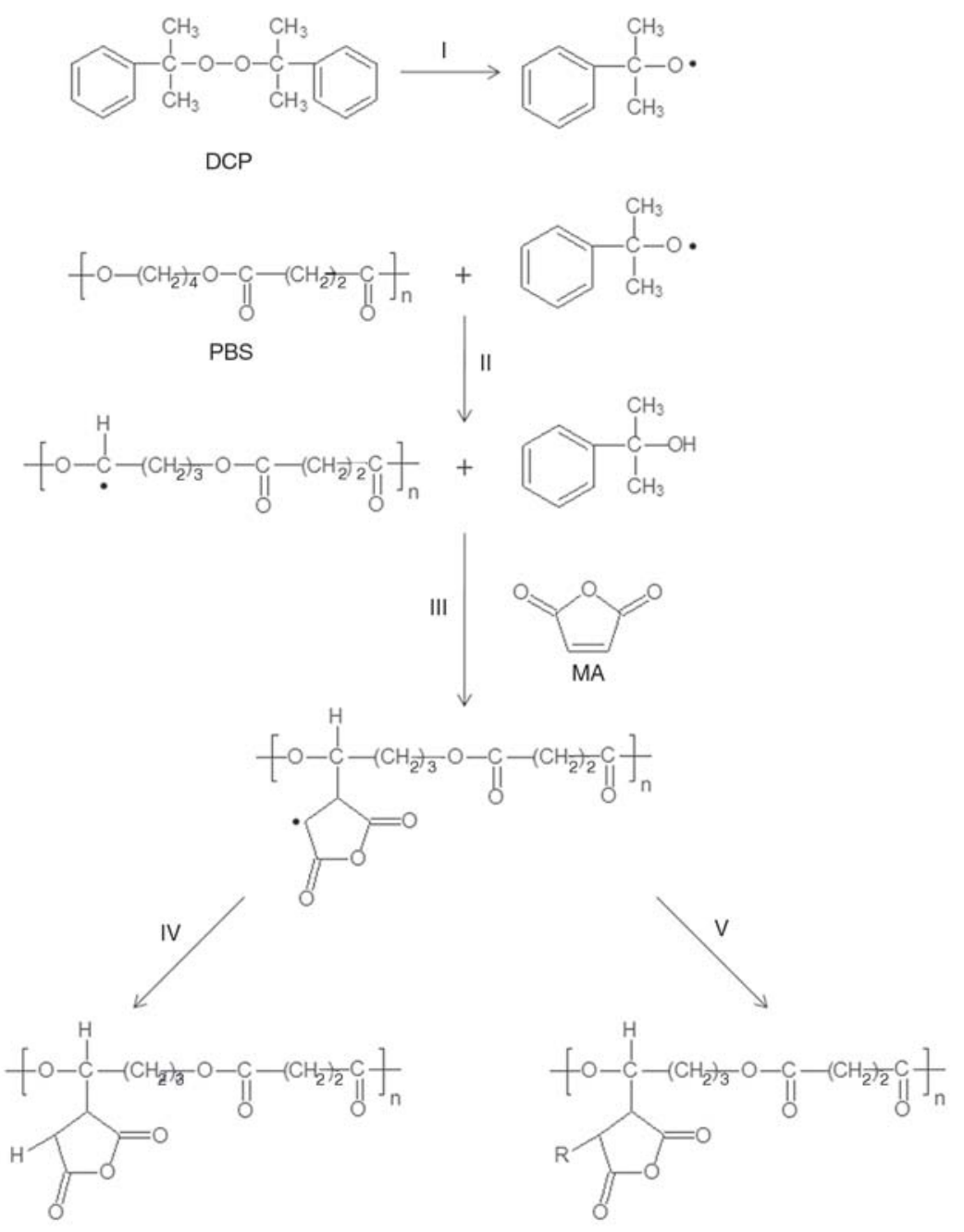

Figure 4. Proposed grafting mechanism of MA onto PBS

Table 3. Mechanical properties of PBS nanocomposites

\begin{tabular}{|l|c|c|c|c|c|c|c|}
\hline \multirow{2}{*}{ Properties } & \multicolumn{7}{c|}{ Compound } \\
\cline { 2 - 7 } & PBS & PBS/C1 & PBS/C2 & PBS/2\%OMMT & PBS/2\%OMMT/C1 & PBS/2\%OMMT/C2 \\
\hline & $32.6 \pm 2.7$ & $29.8 \pm 0.69$ & $29.0 \pm 2.2$ & $33.6 \pm 1.2$ & $34.2 \pm 1.3$ & $37.1 \pm 1.3$ \\
\hline Strength [MPa] & $589 \pm 6.8$ & $603 \pm 12$ & $599 \pm 14$ & $631 \pm 9.1$ & $634 \pm 4.3$ & $650 \pm 7.2$ \\
\hline Modulus [MPa] & $10.9 \pm 2.6$ & $6.99 \pm 0.45$ & $6.67 \pm 1.4$ & $12.9 \pm 2.4$ & $10.5 \pm 2.0$ & $12.5 \pm 1.8$ \\
\hline Elongation at break [\%] & \multicolumn{7}{|c|}{ Flexural } \\
\hline
\end{tabular}

higher intercalation of the OMMT galleries, which in turn provides a better dispersion of the clay platelets.

The addition of stiff reinforcements, such as OMMT was able to improve both the tensile and the flexural modulus [15-16, 29]. Table 3 shows that the modulus is slightly increased after the incorporation of PBS-g-MA into the nanocomposites. Moreover, nanocomposite compatibilized with $\mathrm{C} 2$ exhibits a higher tensile modulus than that of compatibilized with C1. Mishra et al. [32] and Tserki et al. [27] explained that the intercalation of polymer chains inside the silicate layers led to an increase in the surface area of interaction between the organoclay and polymer matrix, subsequently caused the modulus enhancement. However, the effect of $G_{\mathrm{d}}$ on the flexural strength and modulus is negligible. Nevertheless, the incorporation of PBS-g-MA does not show significant effect on the elongation at break. It is believed that the better interfacial interaction between polymer and organoclay has compensated the negative effect of MA that was often reported to 
reduce the elongation at break $[22,32]$. The improved matrix-filler interfacial interactions could enhance the stress transfer efficiency from matrix to filler when the composites were subjected to an external load, subsequently yield a higher elongation at break. Hence, the elongation at break in PBS/2\%OMMT/ $\mathrm{C} 2$ was retained. The improvement in mechanical properties could therefore be a combination of improved clay dispersion and interfacial interactions between polymer and clay.

\subsubsection{X-ray diffraction (XRD)}

The OMMT dispersion in the nanocomposites was studied through the XRD analysis. Figure 5 presents the wide-angle XRD patterns of OMMT and the nanocomposites. A clear peak showing the interlayer spacing associated with the $d_{001}$ plane of MMT was observed. The XRD spectrum of OMMT exhibits a broad intense peak at $2 \theta=3.17^{\circ}$, corresponding to a $d_{001}$ spacing of $2.79 \mathrm{~nm}$. It is clear that the peaks tend to broaden and shift toward a lower value of $2 \theta$ after the formation of nanocomposites, suggesting the formation of intercalated and exfoliated structures in the nanocomposites [33-35]. The XRD patterns of $\mathrm{PBS} / 2 \% \mathrm{OMMT}$, PBS/2\%OMMT/ $\mathrm{C} 1$ and $\mathrm{PBS} / 2 \% \mathrm{OMMT} / \mathrm{C} 2$ reveal the diffraction peaks at $2 \theta=2.46,2.32$ and $2.23^{\circ}$, corresponding to the $d_{001}$ spacing of $3.59,3.81$ and $3.95 \mathrm{~nm}$, respectively.

Addition of PBS-g-MA into the nanocomposites is proven to further facilitate the expansion of gallery space between the organoclay layers. Moreover, nanocomposite compatibilized with $\mathrm{C} 2$ shows better OMMT dispersion with larger $d_{001}$ spacing than

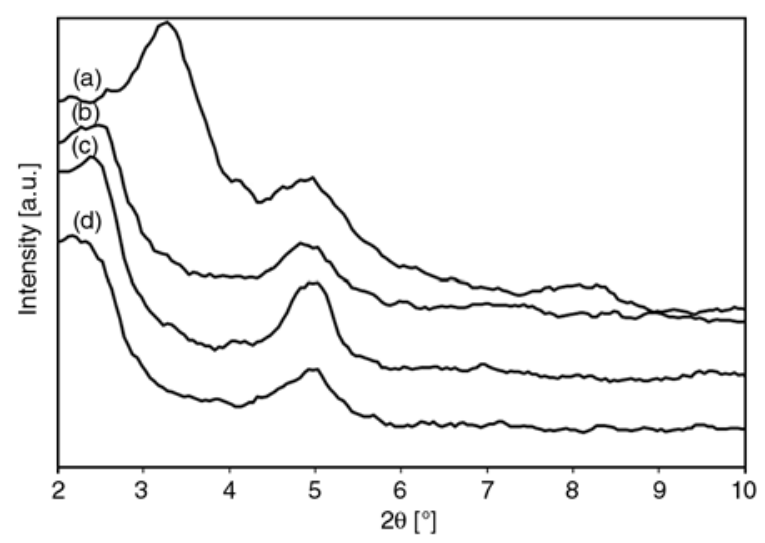

Figure 5. XRD patterns of (a) OMMT, (b) PBS/2\%OMMT, (c) $\mathrm{PBS} / 2 \% \mathrm{OMMT} / \mathrm{C} 1$ and (d) $\mathrm{PBS} / 2 \% \mathrm{OMMT} /$ $\mathrm{C} 2$ that with $\mathrm{C} 1$. This can be correlated with the greater enhancement in mechanical properties of $\mathrm{C} 2 \mathrm{com}-$ patibilized nanocomposite, as discussed earlier.

\subsubsection{Transmission electron microscopy (TEM)}

TEM images of the nanocomposites are displayed in Figure 6. As observed from Figure 6a, a mixed region of tactoids, stacks of intercalated clay platelets, and individual exfoliated platelets are present in the uncompatibilized nanocomposites. After compatibilization using PBS-g-MA, a higher degree of intercalated and exfoliated clay platelets has been obtained, as presented in Figure $6 \mathrm{~b}$ and $6 \mathrm{c}$. The clay agglomerations and tactoids were obviously reduced, contributed to better filler dispersion. The TEM images have provided a direct visualization of the improved dispersion of OMMT in PBS matrix, which is in good agreement with the observed mechanical properties and $\mathrm{XRD}$ results. It is also noted that $\mathrm{C} 2$ compatibilized nanocomposite shown better clay dispersion as compared to $\mathrm{C} 1$ compatibilized nanocomposite.

\subsubsection{Scanning electron microscopy (SEM)}

Figure 7 shows the tensile fractured surface of PBS and its nanocomposites. PBS exhibits a semi-ductile fracture behavior, indicated by the relatively smooth and clear surface with fibrils that formed a web-like structure. In Figure 7b, fractured surface of PBS/ 2\%OMMT nanocomposites reveals a reduction in the fibrillation of PBS, due to the stiffening effect after OMMT addition. This is in agreement with the modulus enhancement as reported previously. Furthermore, distinct phase separation between the OMMT platelets and the PBS matrix is noticeable. The formation of microcavities at the filler-matrix interface is caused by the poor compatibility between PBS and OMMT, which is the main reason of the limited properties enhancement.

Figure $7 \mathrm{c}$ and $7 \mathrm{~d}$ show the tensile fractured surface of the compatibilized nanocomposites. The disappearance of matrix fibrillation from the fracture surface is due to the stiffening effect after incorporation of PBS-g-MA. Besides that, there is no clear filler delamination from the PBS matrix, confirms the improved filler-matrix interactions in the PBS/OMMT nanocomposites after compatibilization. 


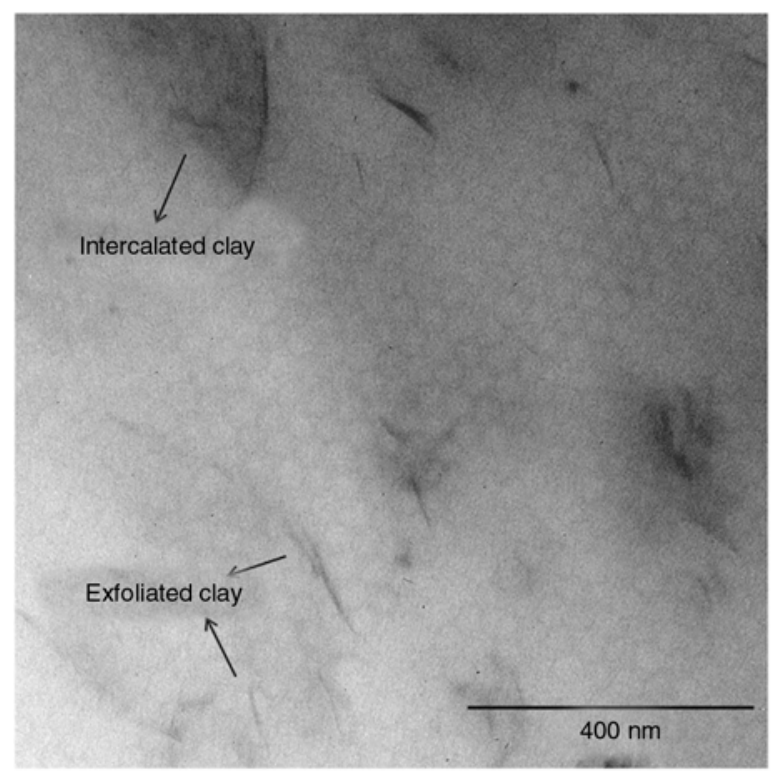

a)

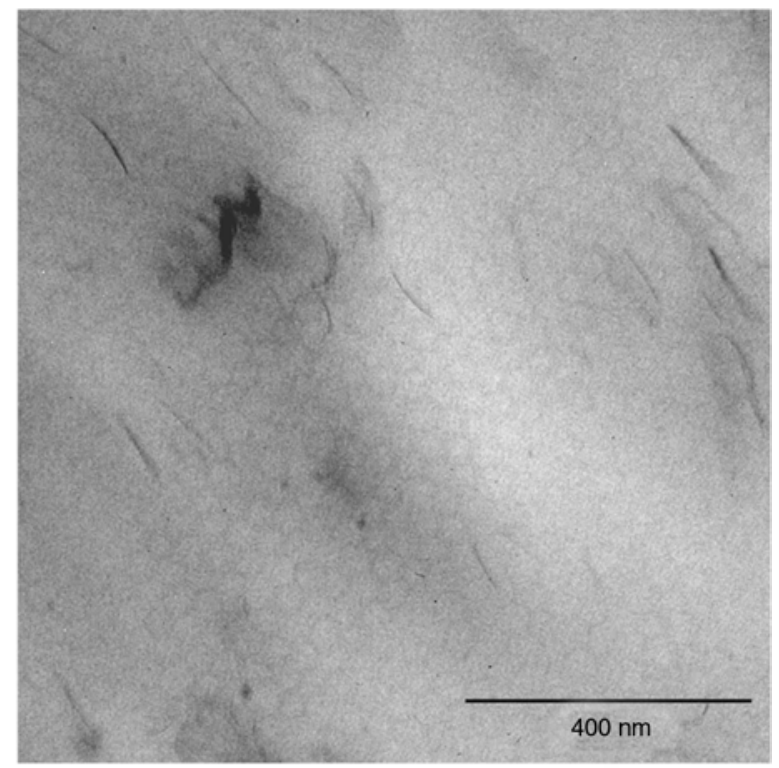

b)

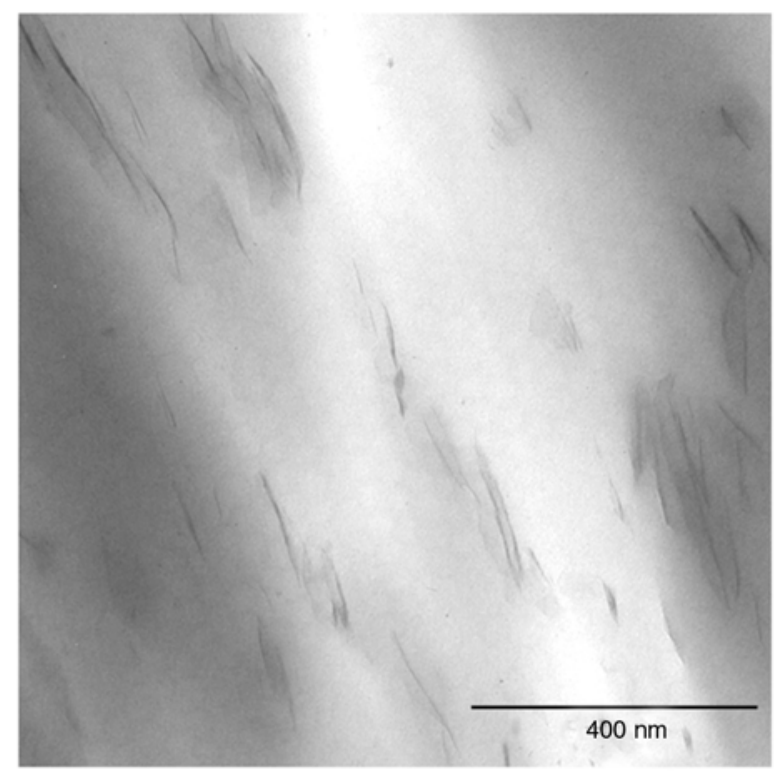

c)

Figure 6. TEM images of (a) PBS/2\%OMMT, (b) PBS/2\%OMMT/C1 and (c) PBS/2\%OMMT/C2

\subsubsection{Differential scanning calorimetry (DSC)}

The thermal behavior of PBS nanocomposites is studied from the DSC analysis and reported in Figure 8. Figure 8 a shows two distinct peaks in the heating scans of PBS and its nanocomposites. Similar observation has been reported by Ray et al. [36] and Vega-Baudrit et al. [37], where they pointed out the existence of two melting peaks was due to the two different types of crystalline lamella presented in PBS. They suggested that the lower melting endotherm is corresponds to the melting of the original crystallites formed at the isothermal crystallization temperature; while the higher melting endotherm reveals the melting of the recrystallized crys- tals. Moreover, an exothermic peak, which resulted from the fusion and recrystallization of PBS crystals during heating [38-39], was found for all the samples prior to the second melting endotherm. Table 4 indicates that the incorporation of PBS-gMA into PBS slightly increased the melting temperature at the low endotherm $\left(T_{\mathrm{m} 1}\right)$. This is assigned to the interfacial chemical reaction between the MA group in PBS-g-MA and carbonyl group in PBS, which affected the melting kinetics of PBS crystals. Melting temperature at the high endotherm $\left(T_{\mathrm{m} 2}\right)$ of PBS did not show any appreciable change after the addition of PBS-g-MA. Moreover, the incorporation of OMMT did not change the $T_{\mathrm{m} 1}$ and $T_{\mathrm{m} 2}$ of 


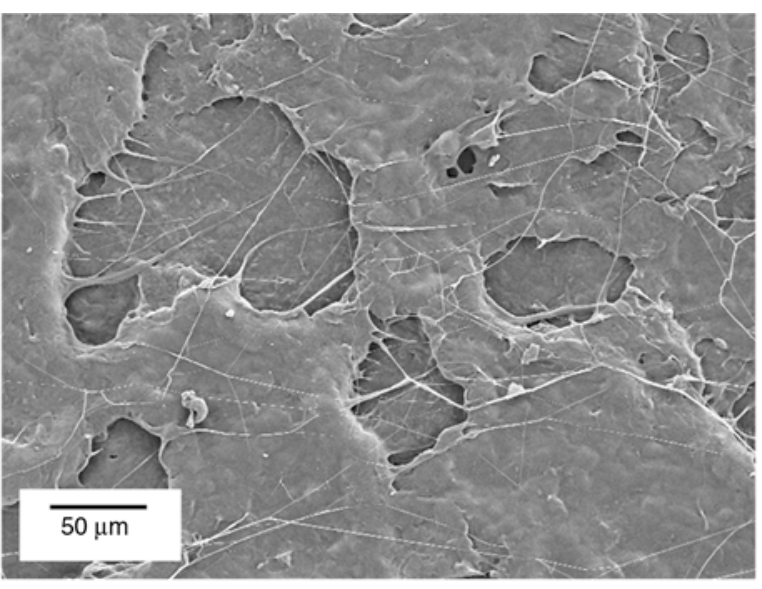

a)

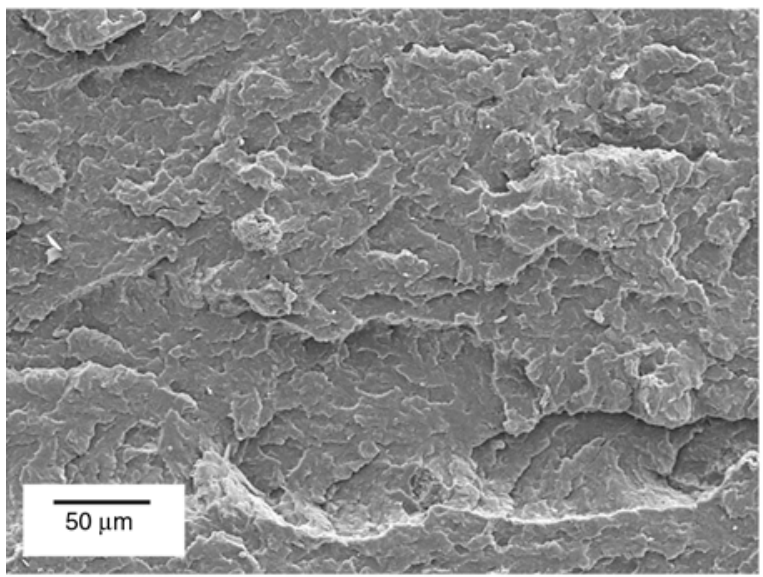

c)

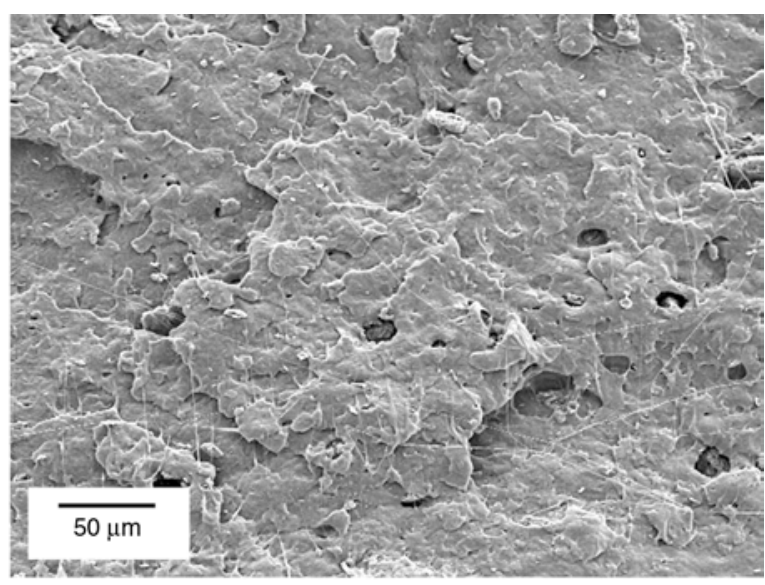

b)

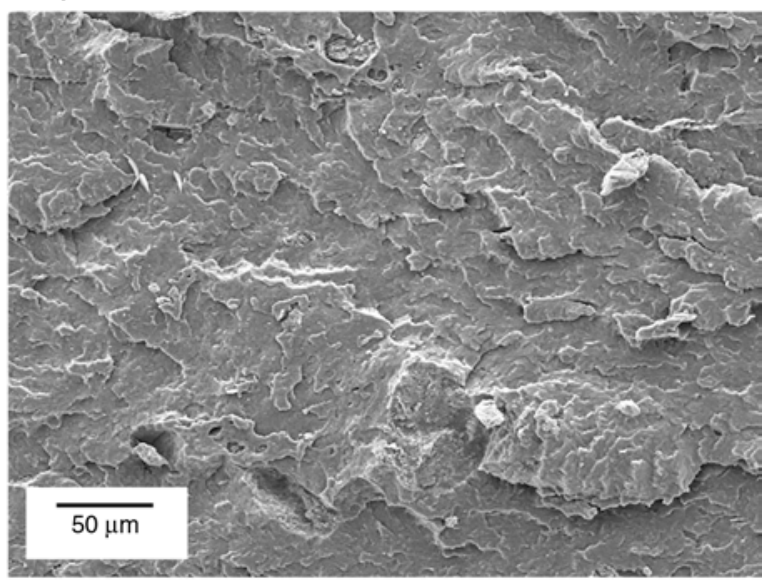

Figure 7. SEM micrographs of the tensile fractured surface of (a) PBS, (b) PBS/2\%OMMT, (c) PBS/2\%OMMT/C1 and (d) $\mathrm{PBS} / 2 \% \mathrm{OMMT} / \mathrm{C} 2$
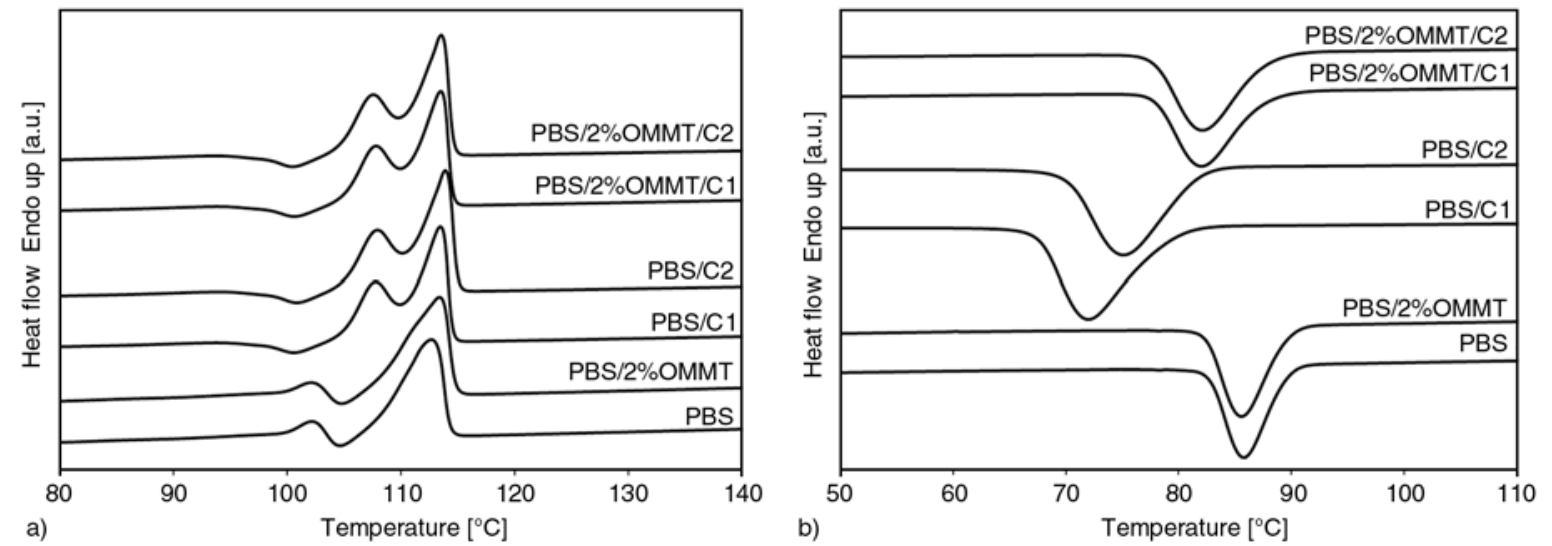

Figure 8. DSC (a) melting and (b) cooling scans of PBS nanocomposites

Table 4. Melting and crystallization behavior of PBS nanocomposites

\begin{tabular}{|l|c|c|c|c|}
\hline \multicolumn{1}{|c|}{ Compound } & $\begin{array}{c}\mathbf{T}_{\mathbf{m} 1} \\
{\left[{ }^{\circ} \mathbf{C}\right]}\end{array}$ & $\begin{array}{c}\mathbf{T}_{\mathbf{m} 2} \\
{\left[{ }^{\circ} \mathbf{C}\right]}\end{array}$ & $\begin{array}{c}\mathbf{T}_{\mathbf{c}} \\
{\left[{ }^{\circ} \mathbf{C}\right]}\end{array}$ & $\begin{array}{c}\chi_{\mathbf{c}} \\
{[\mathbf{\%}]}\end{array}$ \\
\hline PBS & 102.2 & 112.4 & 85.9 & 57.6 \\
\hline PBS/2\%OMMT & 102.1 & 113.4 & 85.6 & 55.7 \\
\hline PBS/C1 & 107.8 & 113.9 & 72.1 & 61.7 \\
\hline PBS/C2 & 107.9 & 114.0 & 75.3 & 62.5 \\
\hline PBS/2\%OMMT/C1 & 107.6 & 113.4 & 82.0 & 64.8 \\
\hline PBS/2\%OMMT/C2 & 107.4 & 113.6 & 82.1 & 65.9 \\
\hline
\end{tabular}

PBS, which is in line with that reported in our previous publications [15-16].

From Figure 8b, it is noted that the incorporation of OMMT into PBS does not provide a significant change in the crystallization temperature $\left(T_{\mathrm{c}}\right)$. However, a slight decreased degree of crystallinity $\left(\chi_{c}\right)$ in $\mathrm{PBS} / 2 \% \mathrm{OMMT}$ nanocomposites has been observed. This is attributed to the physical hindrance of OMMT platelets for the mobility and 
flexibility of the polymer chains to fold and join the crystallization growth front $[14-15,29]$. An obvious reduction in $T_{\mathrm{c}}$ is observed in the PBS/PBS-gMA blend, accompanied with a slight improvement in $\chi_{\mathrm{c}}$ to 61.7 and $62.5 \%$ in the presence of $\mathrm{C} 1$ and $\mathrm{C} 2$, respectively. The reduction in $T_{\mathrm{c}}$ is attributed to slower crystal growth generated by the interactions between PBS and PBS-g-MA, as mentioned earlier. In addition, the increased $\chi_{\mathrm{c}}$ reveals that PBS-g-MA acts as a heterogeneous nucleating agent, creating the nucleating sites for crystallization process to occur [40]. Nanocomposite that compatibilized by $\mathrm{C} 2$ exhibits higher $\chi_{\mathrm{c}}$ than that compatibilized by $\mathrm{C} 1$, owing to the higher $G_{\mathrm{d}}$ of $\mathrm{C} 2$. Besides that, the $\chi_{\mathrm{c}}$ of nanocomposites is increased by 16.3 and $18.3 \%$ after compatibilized with $\mathrm{C} 1$ and $\mathrm{C} 2$, respectively. Thus, it is understood that the increment in crystallinity could also be partially responsible for the increase in mechanical properties. However, the compatibilized nanocomposites show $T_{\mathrm{c}}$ at $\sim 82{ }^{\circ} \mathrm{C}$, which is higher than that of the PBS/PBS-g-MA blend. A study done by $\mathrm{Xu}$ et al. [41] claimed that the improved interaction between polymer and organoclay after compatibilization has caused the immobilizing of some polymer chains. This contributes to the crystallization of polymer matrix, leads to the crystallization at a higher $T_{\mathrm{c}}$. However, the existence of clay platelets may also create a physical hindrance upon the crystal growth. Therefore, the $T_{\mathrm{c}}$ is still lower than that of the neat PBS.

\subsubsection{Thermogravimetry (TGA)}

The thermal stability of PBS nanocomposites was assessed by TGA, where the sample weight loss due to volatilization of degraded by-products is monitored in function of a temperature ramp, as pre-

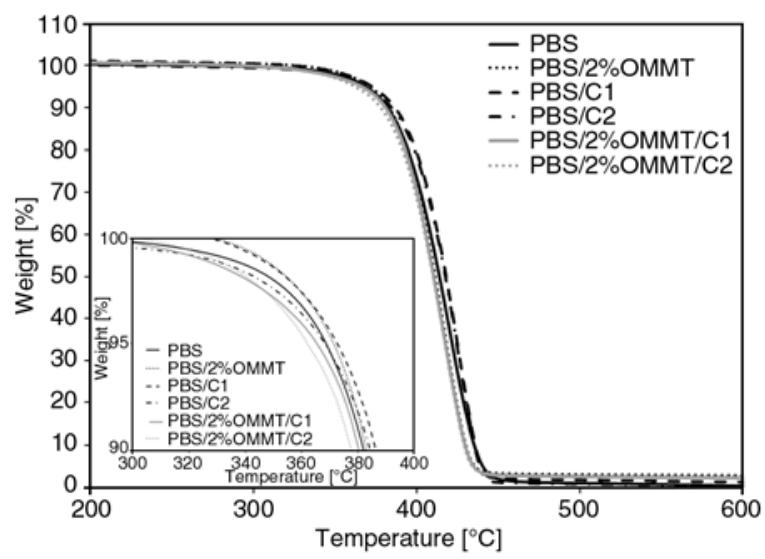

Figure 9. TGA curves of PBS nanocomposites (the insert shows the zoom of the selected area) sented in Figure 9. The TGA curves display a single-stage degradation process starting at $\sim 300^{\circ} \mathrm{C}$ and ending at $\sim 470^{\circ} \mathrm{C}$, which correspondens to the structural decomposition of the polymers. The single-stage decomposition of compatibilized PBS nanocomposites provides an evidence that no formation of crosslinking in the PBS-g-MA. The nanocomposites show a weight loss of 97.4, 98.1 and $97.6 \%$, for the PBS/2DM, PBS/2DM/C1 and PBS/ $2 \mathrm{DM} / \mathrm{C} 2$ nanocomposites, respectively. There is approximately $2-3 \mathrm{wt} \%$ of char residue remained after the polymer decomposition.

According to the literature, the decomposition temperature can be studied through various points in the TGA curves. In this work, the onset of the decomposition temperature $\left(T_{\mathrm{d} 5}\right)$ was determined by the temperature at 5\% weight loss [42-44], whilst the decomposition temperature at the point of greatest rate of change on the weight loss curve $\left(T_{\mathrm{dmax}}\right)$ was measured through the derivative weight loss curves (Figure 10). Table 5 shows that the addition of OMMT into PBS does not produce any appreciable changes in the $T_{\mathrm{d} 5}$ and $T_{\mathrm{dmax}}$. This implies that the presence of OMMT does not provide a significant effect in improving the thermal stability as usually reported by numerous researchers [45-48]. Even though the organoclay was often reported on its

Table 5. Thermal stability of PBS nanocomposites

\begin{tabular}{|l|c|c|}
\hline \multicolumn{1}{|c|}{ Compound } & $\begin{array}{c}\mathbf{T}_{\mathbf{d} 5} \\
{\left[{ }^{\circ} \mathbf{C}\right]}\end{array}$ & $\begin{array}{c}\mathbf{T}_{\text {dmax }} \\
{\left[{ }^{\circ} \mathbf{C}\right]}\end{array}$ \\
\hline PBS & 368.7 & 411.9 \\
\hline PBS/2\%OMMT & 371.4 & 407.8 \\
\hline PBS/C1 & 372.8 & 427.4 \\
\hline PBS/C2 & 369.3 & 426.0 \\
\hline PBS/2\%OMMT/C1 & 365.4 & 407.2 \\
\hline PBS/2\%OMMT/C2 & 362.1 & 407.3 \\
\hline
\end{tabular}

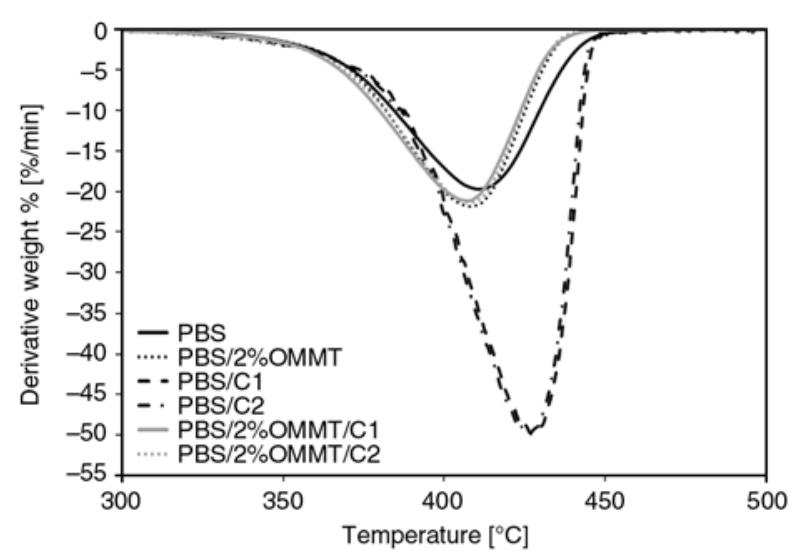

Figure 10. Derivative weight loss curves of PBS nanocomposites 
ability to enhance the thermal stability, the organic surfactant on the organoclay could suffer from decomposition following the Hoffmann elimination reaction [49-50]. The alkylammonium cations present on the OMMT surface is decomposed into an olefin and an amine, leaves an acid proton on the OMMT surface. This acid site is able to catalyze the degradation of the polymers at elevated temperatures, resulting in thermal instability of the material. On the other hand, the incorporation of PBS-g-MA into PBS does not show any significant change in the $T_{\mathrm{d} 5}$, but increased the $T_{\mathrm{dmax}}$. The enhancement in the thermal properties may due to the improved interactions between PBS and PBS-g-MA [51]. For the compatibilized nanocomposites, the improved filler-matrix interaction in the nanocomposites does not favor the thermal stability. This means that the presence of alkylammonium groups on the OMMT surface has catalyzed the degradation, leads to a reduction in the thermal stability.

\subsubsection{Fourier transform infrared (FTIR) spectroscopy}

It was discussed earlier that the polar MA groups may interact with the amine groups on the OMMT surface by forming hydrogen bonding on one side, and with the carbonyl groups on the PBS chains on the other side. This is further verified from the FTIR spectroscopy as presented in Figure 11. The characteristic peaks of PBS-g-MA at 1780 and $1849 \mathrm{~cm}^{-1}$ disappeared in the compatibilized PBS nanocomposites. The peak intensities of PBS nanocomposites were weakened after compatibilization, typically for the ester function groups in PBS (1144$1264 \mathrm{~cm}^{-1}$ and $1710-1713 \mathrm{~cm}^{-1}$ ). Furthermore, the

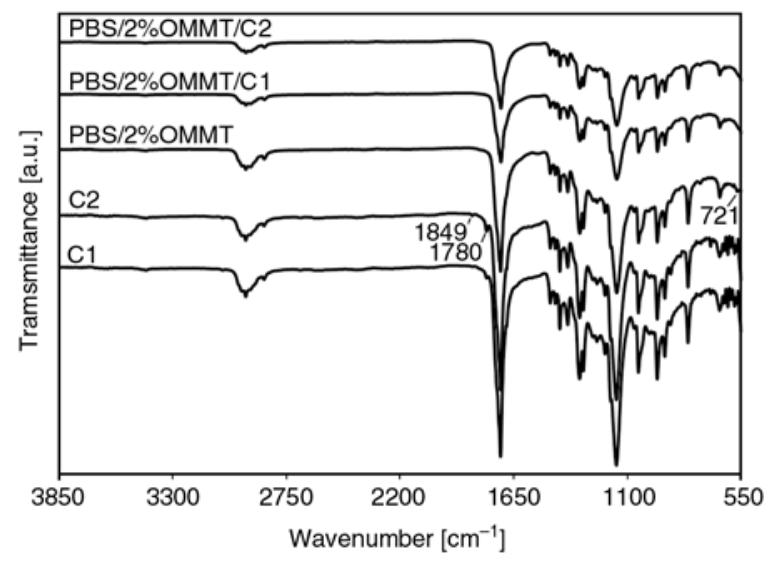

Figure 11. FTIR spectra of PBS-g-MA and nanocomposites before and after compatibilization transmittance band $\left(721 \mathrm{~cm}^{-1}\right)$ corresponding to the amine functional groups of octadecylamine in OMMT vanished after compatibilization. Hence, it is quite reasonable to suppose that partial hydrolysis occurred in the anhydride functional groups interacting with the alkylammonium and the hydroxyl groups on OMMT surface, and with the carbonyl groups in PBS by forming hydrogen bonds [52].

\section{Conclusions}

This study successfully demonstrated the synthesis of PBS-g-MA through reactive grafting process at the diol unit of PBS, as confirmed by FTIR and NMR spectroscopy. PBS-g-MA produced by using higher initiator content exhibited higher degree of grafting. Mechanical properties of PBS nanocomposites were improved after the incorporation of PBS-g-MA as compatibilizer. The compatibilizer not only enhanced the intercalation of polymer chains between the silicate galleries, but also improved the filler-matrix interaction. PBS-g-MA that prepared at higher initiator content was able to provide a better compatibilizing effect, caused by the higher degree of grafting. Besides that, PBS-g-MA could act as a nucleating agent to increase the degree of crystallinity, which is partially responsible for the improvements in mechanical properties. However, the effect of PBS-g-MA on the thermal stability of nanocomposites is negligible.

\section{Acknowledgements}

The financial support of USM Research University Cluster Grant (1001/PKT/8640012), USM Incentive Grant (1001/ PBAHAN/8021011), USM Research University Postgraduate Research Grant Scheme (1001/PBAHAN/8044004), USM Fellowship and USM Post-doctoral Fellowship is gratefully acknowledged.

\section{References}

[1] LeBaron P. C., Wang Z., Pinnavaia T. J.: Polymer-layered silicate nanocomposites: An overview. Applied Clay Science, 15, 11-29 (1999). DOI: $10.1016 / \mathrm{S} 0169-1317(99) 00017-4$

[2] Alexandre M., Dubois P.: Polymer-layered silicate nanocomposites: Preparation, properties and uses of a new class of materials. Materials Science and Engineering R: Reports, 28, 1-63 (2000). DOI: $10.1016 / \mathrm{S} 0927-796 \mathrm{X}(00) 00012-7$ 
[3] Rajesh J. J., Soulestin J., Lacrampe M. F., Krawczak P.: Effect of injection molding parameters on nanofillers dispersion in masterbatch based PP-clay nanocomposites. Express Polymer Letters, 6, 237-248 (2012).

DOI: 10.3144/expresspolymlett.2012.26

[4] Li Y., Zhao B., Xie S., Zhang S.: Synthesis and properties of poly(methyl methacrylate)/montmorillonite (PMMA/MMT) nanocomposites. Polymer International, 52, 892-898 (2003).

DOI: $10.1002 /$ pi.1121

[5] Zhao C., Qin H., Gong F., Feng M., Zhang S., Yang M.: Mechanical, thermal and flammability properties of polyethylene/clay nanocomposites. Polymer Degradation and Stability, 87, 183-189 (2005).

DOI: $10.1016 /$ j.polymdegradstab.2004.08.005

[6] Rousseaux D. D. J., Sallem-Idrissi N., Baudouin A-C., Devaux J., Godard P., Marchand-Brynaert J., Sclavons M.: Water-assisted extrusion of polypropylene/clay nanocomposites: A comprehensive study. Polymer, 52, 443-451 (2011).

DOI: $10.1016 /$ j.polymer.2010.11.027

[7] Yano K., Usuki A., Okada A., Kurauchi T., Kamigaito O.: Synthesis and properties of polyimide-clay hybrid. Journal of Polymer Science Part A: Polymer Chemistry, 31, 2493-2498 (1993).

DOI: $10.1002 /$ pola.1993.080311009

[8] Gilman J. W., Jackson C. L., Morgan A. B., Harris R., Manias E., Giannelis E. P., Wuthenow M., Hilton D., Phillips S. H.: Flammability properties of polymerlayered-silicate nanocomposites. Polypropylene and polystyrene nanocomposites. Chemistry of Materials, 12, 1866-1873 (2000).

DOI: $10.1021 / \mathrm{cm} 0001760$

[9] Timochenco L., Grassi V. G., Dal Pizzol M., Costa J. M., Castellares L. G., Sayer C., Machado R. A. F., Araújo P. H. H.: Swelling of organoclays in styrene. Effect on flammability in polystyrene nanocomposites. Express Polymer Letters, 4, 500-508 (2010). DOI: $10.3144 /$ expresspolymlett.2010.63

[10] Okamoto K., Ray S. S., Okamoto M.: New poly(butylene succinate)/layered silicate nanocomposites. II. Effect of organically modified layered silicates on structure, properties, melt rheology, and biodegradability. Journal of Polymer Science Part B: Polymer Physics, 41, 3160-3172 (2003).

DOI: $10.1002 /$ polb.10708

[11] Someya Y., Nakazato T., Teramoto N., Shibata M.: Thermal and mechanical properties of poly(butylene succinate) nanocomposites with various organo-modified montmorillonites. Journal of Applied Polymer Science, 91, 1463-1475 (2003).

DOI: $10.1002 / \mathrm{app} .13366$

[12] Chen G-X., Kim E-S., Yoon J-S.: Poly(butylene succinate)/twice functionalized organoclay nanocomposites: Preparation, characterization, and properties. Journal of Applied Polymer Science, 98, 1727-1732 (2005). DOI: $10.1002 /$ app.22264
[13] Fujimaki T.: Processability and properties of aliphatic polyesters, 'BIONOLLE', synthesized by polycondensation reaction. Polymer Degradation and Stability, 59, 209-214 (1998). DOI: 10.1016/S0141-3910(97)00220-6

[14] Chieng B. W., Ibrahim N. A., Wan Yunus W. M. Z.: Effect of organo-modified montmorillonite on poly (butylene succinate)/poly(butylene adipate-co-terephthalate) nanocomposites. Express Polymer Letters, 4, 404-414 (2010).

DOI: $10.3144 /$ expresspolymlett.2010.51

[15] Phua Y. J., Chow W. S., Mohd Ishak Z. A.: Poly(butylene succinate)/ organo-montmorillonite nanocomposites: Effects of the organoclay content on mechanical, thermal, and moisture absorption properties. Journal of Thermoplastic Composite Materials, 24, 133-151 (2010).

DOI: $10.1177 / 0892705710376469$

[16] Phua Y. J., Chow W. S., Mohd Ishak Z. A.: Mechanical properties and structure development in poly(butylene succinate)/organo-montmorillonite nanocomposites under uniaxial cold rolling. Express Polymer Letters, 5, 93-103 (2011).

DOI: $10.3144 /$ expresspolymlett.2011.11

[17] Nwabunma D., Kyu T.: Polyolefin composites. WileyInterscience, New Jersey (2008).

[18] Pegoretti A., Dorigato A., Penati A.: Tensile mechanical response of polyethylene-clay nanocomposites. Express Polymer Letters, 1, 123-131 (2007). DOI: 10.3144/expresspolymlett.2007.21

[19] Petersson L., Oksman K., Mathew A. P: Using maleic anhydride grafted poly(lactic acid) as a compatibilizer in poly(lactic acid)/layered-silicate nanocomposites. Journal of Applied Polymer Science, 102, 1852-1862 (2006).

DOI: 10.1002/app.24121

[20] Lai S-M., Li H-C., Liao Y-C.: Properties and preparation of compatibilized nylon 6 nanocomposites/ABS blends: Part II - Physical and thermal properties. European Polymer Journal, 43, 1660-1671 (2007).

DOI: $10.1016 /$ j.eurpolymj.2007.02.009

[21] Kusmono, Mohd Ishak Z. A., Chow W. S., Takeichi T., Rochmadi: Enhancement of properties of PA6/PP nanocomposites via organic modification and compatibilization. Express Polymer Letters, 2, 655-664 (2008). DOI: 10.3144 /expresspolymlett.2008.78

[22] López-Quintanilla M. L., Sánchez-Valdés S., Ramos de Valle L. F., Medellín-Rodríguez F. J.: Effect of some compatibilizing agents on clay dispersion of polypropylene-clay nanocomposites. Journal of Applied Polymer Science, 100, 4748-4756 (2006). DOI: $10.1002 /$ app. 23262 
[23] Kusmono, Mohd Ishak Z. A., Chow W. S., Takeichi T., Rochmadi: Compatibilizing effect of SEBS-g-MA on the mechanical properties of different types of OMMT filled polyamide 6/polypropylene nanocomposites. Composites Part A: Applied Science and Manufacturing, 39, 1802-1814 (2008).

DOI: 10.1016/j.compositesa.2008.08.009

[24] Mohanty S., Nayak S. K.: Effect of clay exfoliation and organic modification on morphological, dynamic mechanical, and thermal behavior of melt-compounded polyamide- 6 nanocomposites. Polymer Composites, 28, 153-162 (2007).

DOI: $10.1002 / p c .20284$

[25] Qiu Z., Yang W.: Crystallization kinetics and morphology of poly(butylene succinate)/poly(vinyl phenol) blend. Polymer, 47, 6429-6437 (2006). DOI: $10.1016 /$ j.polymer.2006.07.001

[26] Mani R., Bhattacharya M., Tang J.: Functionalization of polyesters with maleic anhydride by reactive extrusion. Journal of Polymer Science Part A: Polymer Chemistry, 37, 1693-1702 (1999).

DOI: $10.1002 /($ SICI)1099-0518(19990601)37:11<1693 $\because$ AID-POLA15>3.0.CO;2-Y

[27] Tserki V., Matzinos P., Panayiotou C.: Novel biodegradable composites based on treated lignocellulosic waste flour as filler. Part II. Development of biodegradable composites using treated and compatibilized waste flour. Composites Part A: Applied Science and Manufacturing, 37, 1231-1238 (2006).

DOI: 10.1016/j.compositesa.2005.09.004

[28] Kim H-S., Lee B-H., Choi S-W., Kim S., Kim H-J.: The effect of types of maleic anhydride-grafted polypropylene (MAPP) on the interfacial adhesion properties of bio-flour-filled polypropylene composites. Composites Part A: Applied Science and Manufacturing, 38, 1473-1482 (2007).

DOI: $10.1016 /$ j.compositesa.2007.01.004

[29] Phua Y. J., Chow W. S., Mohd Ishak Z. A.: The hydrolytic effect of moisture and hygrothermal aging on poly(butylene succinate)/organo-montmorillonite nanocomposites. Polymer Degradation and Stability, 96, 1194-1203 (2011).

DOI: $10.1016 /$ j.polymdegradstab.2011.04.017

[30] Sclavons M., Laurent M., Devaux J., Carlier V.: Maleic anhydride-grafted polypropylene: FTIR study of a model polymer grafted by ene-reaction. Polymer, 46, 8062-8067 (2005).

DOI: $10.1016 /$ j.polymer.2005.06.115

[31] Chow W. S., Mohd Ishak Z. A., Karger-Kocsis J., Apostolov A. A., Ishiaku U. S.: Compatibilizing effect of maleated polypropylene on the mechanical properties and morphology of injection molded polyamide 6/ polypropylene/organoclay nanocomposites. Polymer, 44, 7427-7440 (2003).

DOI: $10.1016 /$ j.polymer.2003.09.006
[32] Mishra J. K., Hwang K-J., Ha C-S.: Preparation, mechanical and rheological properties of a thermoplastic polyolefin (TPO)/organoclay nanocomposite with reference to the effect of maleic anhydride modified polypropylene as a compatibilizer. Polymer, 46, 19952002 (2005).

DOI: $10.1016 /$ j.polymer.2004.12.044

[33] Shen Z., Simon G. P., Cheng Y-B.: Comparison of solution intercalation and melt intercalation of polymer-clay nanocomposites. Polymer, 43, 4251-4260 (2002).

DOI: 10.1016/S0032-3861(02)00230-6

[34] Parija S., Nayak S. K., Verma S. K., Tripathy S. S.: Studies on physico-mechanical properties and thermal characteristics of polypropylene/layered silicate nanocomposites. Polymer Composites, 25, 646-652 (2004). DOI: $10.1002 /$ pc.20059

[35] Samal S. K., Nayak S. K., Mohanty S.: Polypropylene nanocomposites: Effect of organo-modified layered silicates on mechanical, thermal \& morphological performance. Journal of Thermoplastic Composite Materials, 21, 243-263 (2008). DOI: $10.1177 / 0892705708089476$

[36] Ray S. S., Bousmina M., Okamoto K.: Structure and properties of nanocomposites based on poly(butylene succinate-co-adipate) and organically modified montmorillonite. Macromolecular Materials and Engineering, 290, 759-768 (2005).

DOI: $10.1002 /$ mame.200500203

[37] Vega-Baudrit J., Sibaja M., Martín-Martínez J. M., Nakayama K., Masuda T., Cao A.: Characterization of the biodegradable polymer bionolle. in 'New developments in polymer analysis, stabilization and degradation' (ed.: Zaikov G. E. Jiménez A.) Nova Science, New York, 57-71 (2005).

[38] Pang M. Z., Qiao J. J., Jiao J., Wang S. J., Xiao M., Meng Y. Z.: Miscibility and properties of completely biodegradable blends of poly(propylene carbonate) and poly(butylene succinate). Journal of Applied Polymer Science, 107, 2854-2860 (2008).

DOI: $10.1002 / a p p .27252$

[39] Chiu F-C., Lai S-M., Chen Y-L., Lee T-H.: Investigation on the polyamide 6/organoclay nanocomposites with or without a maleated polyolefin elastomer as a toughener. Polymer, 46, 11600-11609 (2005). DOI: 10.1016/j.polymer.2005.09.077

[40] Minhaz-U1 Haque M., Alvarez V., Paci M., Pracella M.: Processing, compatibilization and properties of ternary composites of Mater-Bi with polyolefins and hemp fibres. Composites Part A: Applied Science and Manufacturing, 42, 2060-2069 (2011). DOI: $10.1016 /$ j.compositesa.2011.09.015 
[41] Xu W., Liang G., Wang W., Tang S., He P., Pan W-P.: Poly(propylene)-poly(propylene)-grafted maleic anhydride-organic montmorillonite (PP-PP-g-MAH-OrgMMT) nanocomposites. II. Nonisothermal crystallization kinetics. Journal of Applied Polymer Science, 88, 3093-3099 (2003).

DOI: $10.1002 / a p p .11974$

[42] Ding C., Jia D., He H., Guo B., Hong H.: How organomontmorillonite truly affects the structure and properties of polypropylene. Polymer Testing, 24, 94-100 (2005).

DOI: 10.1016/j.polymertesting.2004.06.005

[43] Kusmono, Mohd Ishak Z. A., Chow W. S., Takeichi T., Rochmadi: Influence of SEBS-g-MA on morphology, mechanical, and thermal properties of PA6/PP/organoclay nanocomposites. European Polymer Journal, 44, 1023-1039 (2008).

DOI: $10.1016 /$ j.eurpolymj.2008.01.019

[44] Cui W., Jiao Q., Zhao Y., Li H., Liu H., Zhou M.: Preparation of poly(ethylene terephthalate)/layered double hydroxide nanocomposites by in-situ polymerization and their thermal property. Express Polymer Letters, 6, 485-493 (2012).

DOI: $10.3144 /$ expresspolymlett.2012.51

[45] Lee D. C., Jang L. W.: Preparation and characterization of PMMA-clay hybrid composite by emulsion polymerization. Journal of Applied Polymer Science, 61, 1117-1122 (1996).

DOI: 10.1002/(SICI)1097-4628(19960815)61:7<1117 :AID-APP7>3.0.CO;2-P

[46] Liang Z-M., Yin J., Wu J-H., Qiu Z-X., He F-F.: Polyimide/montmorillonite nanocomposites with photolithographic properties. European Polymer Journal, 40, 307-314 (2004).

DOI: 10.1016/j.eurpolymj.2003.09.020
[47] Zhu J., Wilkie C. A.: Thermal and fire studies on polystyrene-clay nanocomposites. Polymer International, 49, 1158-1163 (2000).

DOI: $10.1002 / 1097-0126(200010) 49: 10<1158:: A I D-$ PI505>3.0.CO;2-G

[48] Song L., Hu Y., Tang Y., Zhang R., Chen Z., Fan W.: Study on the properties of flame retardant polyurethane/organoclay nanocomposite. Polymer Degradation and Stability, 87, 111-116 (2005).

DOI: $10.1016 /$ j.polymdegradstab.2004.07.012

[49] Cai Y., Wu N., Wei Q., Zhang K., Xu Q., Gao W., Song L., Hu Y.: Structure, surface morphology, thermal and flammability characterizations of polyamide 6/organicmodified Fe-montmorillonite nanocomposite fibers functionalized by sputter coating of silicon. Surface and Coatings Technology, 203, 264-270 (2008). DOI: $10.1016 /$ j.surfcoat.2008.08.076

[50] Cui L., Khramov D. M., Bielawski C. W., Hunter D. L., Yoon P. J., Paul D. R.: Effect of organoclay purity and degradation on nanocomposite performance, Part 1: Surfactant degradation. Polymer, 49, 3751-3761 (2008). DOI: $10.1016 /$ j.polymer.2008.06.029

[51] Zhai H., Xu W., Guo H., Zhou Z., Shen S., Song Q.: Preparation and characterization of PE and PE-g-MAH/ montmorillonite nanocomposites. European Polymer Journal, 40, 2539-2545 (2004). DOI: $10.1016 / j$.eurpolymj.2004.07.009

[52] Lonkar S. P., Therias S., Leroux F., Gardette J. L., Singh R. P.: Influence of reactive compatibilization on the structure and properties of $\mathrm{PP} / \mathrm{LDH}$ nanocomposites. Polymer International, 60, 1688-1696 (2011). DOI: $10.1002 /$ pi.3129 